\title{
“A COMUNICAÇÃO É A CIÊNCIA DO SÉCULO XXI"
}

Edição: Márcio Gonçalves e Thayz Guimarães.

Reportagem: Thayz Guimarães, Bruna Rodrigues, Rafael Barbosa, Júlio Altieri e Carmen Prata.

Produção: Thayz Guimarães, Bruna Rodrigues, Claudia Bianco, Rafael Barbosa, Maíra Alves e Vaniele Barreiros.

Guimarães, Ropdrigues, Barbosa, Altieri, Prata

Marialva Barbosa, presidente da Intercom, falou com exclusividade ao grupo de pesquisa Livros e Cultura Letrada, da Faculdade de Comunicação Social da UERJ, sobre questóes atuais relativas aos campos da Comunicação e da História, do impresso e do digital e de seus próximos projetos; a pesquisadora afirmou que a Comunicação não é mais o patinho feio das Humanidades nem deve ser considerado como "campo jovem"; para ela há um absoluto exagero presentista nos estudos da área. 
Professora Titular de Jornalismo da Universidade Federal do Rio de Janeiro (UFRJ) e Professora Titular de Jornalismo aposentada da Universidade Federal Fluminense (UFF), onde trabalhou por 31 anos, de 1979 a 2010, Marialva Barbosa possui graduação em Comunicação Social pela Universidade Federal Fluminense (1976), e mestrado (1992) e doutorado (1996) em História pela Universidade Federal Fluminense. O pós-doutorado em Comunicação foi concluído, em 1999, pelo LAIOS-CNRS, em Paris, França. Diretora Científica da Intercom de 2009 a 2011, atualmente é Presidente da Intercom, já tendo ocupado a vice-presidência entre os anos de 2011 e 2014. Seu livro História Cultural da Imprensa - Brasil 1900-2000 foi ganhador da Medalha Carlos Eduardo Lins e Silva, outorgada pela Intercom, em 2007, às mais representativas publicaçóes lançadas naquele ano. Ganhou o prêmio Luiz Beltrão de Ciências da Comunicação, categoria Maturidade Acadêmica, em 2008, "pelo conjunto da obra constituída por estudos relevantes, nacionalmente reconhecidos na área de Comunicação". Foi a primeira Cientista do estado do Rio de Janeiro na área de Comunicação pela FAPERJ. Publicou História da Comunicação no Brasil (Vozes, 2013), História Cultural da Imprensa - 1900-2000 (MAUADX, 2007) e História Cultural da Imprensa - 1800-1900 (MAUADX, 2010). Organizou dezenas de livros e publicou diversos de capítulos de livros em obras organizadas no Brasil e no exterior. Possui dezenas de artigos em revistas nacionais e internacionais. No momento, se dedica a pesquisar os jornais manuscritos brasileiros do século XIX e a outras investigações que estabelecem uma interconexão entre história e comunicação. É pesquisadora $1 \mathrm{D}$ do $\mathrm{CNPq}$.

Na Introduçáo do livro História da Comunicação no Brasil a senhora diz que o método utilizado se baseia na construçáo de casos particulares em direção a generalizaçóes. De que forma isso pode interferir na representatividade efetiva de um período histórico? Como proceder para que náo aconteçam generalizaçóes sem fundamento ao utilizar esse tipo de metodologia?

De maneira geral, esse é o grande dilema da História. O argumento de muitos historiadores, inclusive do próprio [Roger] Chartier, é que em tempos de globalização, o que interessa à História é falar de universos bastante específicos. Usando a expressão do [Jacques] Revel, em "jogos de escala diminuta", uma vez que, como podemos fazer uma história dos particularismos sem caminhar em direção a uma história global da civilização tal como se tinha no século XIX, não nos mesmos parâmetros, mas na mesma perspectiva, em um mundo global? Dessa forma, esse não é um dilema da História da Comunicação, mas sim um dilema da História, isto é, o que a gente vai fazer em termos de estudos históricos? Será que estudar, por exemplo, com jogos de escala menor, como a micro-história, daria conta das transformaçóes, das características, das ingerências de outros espaços sociais, de outros universos de natureza histórica? Ou em um mundo em que se percebe uma abolição cada vez maior dos 
espaços, uma nova reconfiguração do tempo, não se estaria caminhando para uma abordagem histórica em que se verificasse cada vez mais o global e não os particularismos? Por isso a questão dos particularismos e das generalizaçôes é sempre um debate enorme dentro do campo da História. No meu livro História da Comunicação no Brasil, aponto dois caminhos possíveis. Primeiro uma ideia de História enquanto historicidade, uma ideia de História muito antiga, em que há excessos de percepção da História como a recuperação da verdade indelével do passado. Essa é uma grande perspectiva. Em segundo lugar estão os estudos que se focam em casos particulares, em regióes, cidades e veículos específicos, por exemplo, não estabelecendo as correlaçôes necessárias daquilo que é observado naquele veículo em relação ao universo mais amplo. O que eu estou dizendo é que o fato de você estudar o veículo não significa que você tenha uma perspectiva particular. Se assim fosse, o [Carlo] Ginzburg, em $O$ Queijo e os Vermes, quando fez o estudo do Menocchio, não estaria falando de uma História mais ampla nem das práticas de leitura de um grupo popular no qual aquela criatura é um intérprete privilegiado ou apenas um entre muitas possibilidades. Então fazer estudos de caso localizados num veículo, numa região, numa cidade, e não correlaciona-los com o contexto comunicacional é que é o particularismo. Quando você correlaciona isso com o contexto comunicacional, você parte dos particularismos para as generalizaçóes. Portanto é uma perspectiva metodológica que considera a metodologia para além de uma simples ferramenta, como abordagem histórica.

\section{A senhora utiliza muitas obras literárias, filmes e novelas no livro. De modo geral, qual é a importância de se usar obras de ficçáo como fonte histórica? E quais sáo os cuidados necessários para a inclusáo dessas fon- tes na metodologia de construçáo de uma pesquisa histórica?}

Este também é um debate antigo na História. Naquela coleção que se tornou um clássico da terceira geração da École des Annales, História: Novos problemas, novas abordagens, novos objetos, tem um texto do Jean Starobinski, um historiador muito importante no estudo da Literatura como fonte da História, em que se discute exatamente qual é esse estatuto da ficção como fonte histórica - e note que estou falando dos anos 1970, não estou falando de hoje. Quando João do Rio escreve $A$ alma encantadora das ruas, ele enquanto João do Rio era um personagem, uma pessoa que vivia naquela ambiência do Rio de Janeiro do início do século XX. Portanto, tudo aquilo que ele viveu está embutido na ficção que ele criou. Essa é a primeira questão, ou seja, as pessoas que escrevem páginas ficcionais são sujeitos históricos e, portanto, são produtos de sua época. Tem uma máxima de História que eu gosto de repetir que é a seguinte: o homem é muito mais produto da sua época do que produto de seu pai e de sua mãe. Tudo que você produz enquanto ação revela as relaçóes, as questóes e as ambiências do mundo no qual você está imerso. Essa é uma perspectiva metodológica de quem utiliza a Literatura como fonte. A segunda questão refere-se ao que é ficcional e ao que é História. Se considerarmos que - e isso não tira da História seu estatuto de Ciência - a História é sempre interpretação criativa do passado, ou seja, que a História não traz o passado para o presente tal como ele se deu, mas que ela produz interpretação desse 
passado no qual estão envolvidas várias questôes, inclusive o olhar do pesquisador que, subjetivamente, faz contato com o passado, isto é, que as fontes não falam, mas sim respondem às perguntas que a gente demanda delas, você está considerando que a História, tal como a ficção, é uma invenção da narrativa. Isso não quer dizer que a História seja ficcional, porque a História, como diz o [Paul] Ricœur, está imbuída daquilo que ele vai chamar de "representância" e de "lugar-tenência", o que quer dizer que ela pode falar o passado, e quando fala o passado, ela não fala outro passado que não o verdadeiro passado. Mas isso não tira dela o estatuto narratológico, de narrativa histórica e, portanto, de imaginação criadora. A Literatura funciona como fonte nesse duplo sentido. Primeiro porque ela foi escrita num tempo e lugar e reproduz aspectos desse tempo e lugar do ponto de vista real e simbólico. E, segundo, porque a História e a Literatura são ambas narrativas, só que a História tem uma convenção com o verossímil, já a Literatura não possui tal obrigação.

Atualmente existem diversas plataformas digitais (celular, tablet, notebook etc.) por meio das quais podemos acessar textos eletrônicos, e cada uma possui características bastante específicas, tanto em nível do software quanto da própria plataforma (bardware), e que marcam distinçóes possíveis no ato da leitura. Diante disso, a senhora acredita que, considerando a abordagem metodológica, nós poderíamos englobar as plataformas digitais de leitura como um todo no estudo do ler ou deveríamos tratar cada suporte individualmente, devido às possibilidades de diferentes condiçóes de práticas de leitura?

Se considerarmos a questão das materialidades tal como Chartier a considera, em que as materialidades determinam não só a forma de se ler, mas o "como" da leitura e até as apropriaçôes feitas a partir desse "como", as materialidades são profundamente diferentes e devem ser abordadas como materialidades. Por exemplo, se eu tenho um códex ou um index, e se no códex eu tenho determinados aspectos que se repetem, claro que eu posso perceber o livro História da Comunicação no Brasil como um suporte tal como o História da Imprensa no Brasil, do Nelson Werneck Sodré, porque ele, enquanto suporte, enquanto materialidade, tem um texto e um paratexto que indicam as formas de me relacionar com aquele impresso. Da mesma forma o tecnológico, mas aí é preciso ver em função da plataforma, da materialidade. Ler em tablet não é a mesma coisa que ler em celular; ler no computador não é a mesma coisa que ler em tablet. A materialidade tablet, por exemplo, pressupóe a possibilidade de leitura fugaz e em movimento - o celular ainda mais do que o tablet -, diante de uma iluminação que é de outra ordem - a iluminação é muito importante. Sem falar nos brancos de leitura e no ato de levantar os olhos e olhar o entorno, o que vai dar outros entornos. Quando eu estou lendo o meu tablet na barca, por exemplo, tenho a possibilidade de ver a paisagem, o que não seria possível diante da tela do meu computador. Então, embora seja tudo ambiente digital, a profunda diferença das materialidades entre uma plataforma e outra nos obriga, do ponto de vista metodológico, a considerar as especificidades.

Quer dizer entáo que, mesmo se falando em leitura digital, há que se 
explicar muito bem, se localizar muito bem que meio digital é esse, certo?

Que meio digital é esse e que conteúdo digital também é esse, porque vai determinar outro tipo de arrumação naquele suporte material. Por exemplo, eu não vejo da mesma forma um vídeo do YouTube e o site do G1. Não é só por conta do conteúdo - o G1 também possui vídeo -, mas é porque tem foto, tem infográfico, tem texto, tem uma multiplicidade de tipologias comunicacionais que estão concentradas no vídeo do YouTube. Eu não vejo da mesma forma a novela quando perco o capítulo ou quando quero ver só um pequeno trecho. Os usos são determinados pela configuração e também pelos conteúdos dessas plataformas. Existe uma linguagem digital do ponto de vista da criaçáo dessa linguagem - através da fórmula matemática binária -, mas os usos que as pessoas fazem da linguagem digital têm transformaçóes exponenciais sobre ela mesma. Quando o celular foi criado, ninguém imaginou os usos que se fariam daquele aparelho. O celular se transformou no que é hoje em função dos usos, por exemplo, ele tornou e-mail uma coisa ultrapassada. Foram criadas opçóes mais instantâneas, mais rápidas, mais diretas, com a possibilidade de interação quase que concomitante, quase, por um istmo de segundo, pergunta e reposta, que reproduzem um pouco a aceleraçáo do mundo contemporâneo, dentro de uma cultura contemporânea que faz com que ele tenha outros usos que a gente jamais imaginou que ele teria. Eu não pesquiso isso, não. É só uma impressão que tenho como historiadora que vê a transformação dos meios na longa duração. E eu costumo dizer que a História da Comunicação é a história humana no sentido de fazer e tornar mais eficiente o ato de comunicar. Se você pensar, a História da Comunicação é só isso, é a tentativa humana de tornar cada vez mais eficiente o ato de comunicar. Aonde vamos parar com isso, eu não sei, mas...

\section{Além de tecer as relaçóes da Comunicaçáo com a História, seus diálogos aconteceram também com a Antropologia, a Filosofia e outros campos do conhecimento. De que forma essas referências ajudaram a de- finir o percurso de suas pesquisas? Como essas relaçóes contribuem para a definiçáo do campo da Comunicação?}

A grande ruptura, a viragem da epistemologia do século XX em direção ao que alguns autores chamam de epistemologia pós-moderna, é que você não tem mais essa delimitação clara entre os campos do saber, e se você pensar que a Comunicação sempre foi o lugar de reunião, de construção e de diálogo com diversos campos do saber, a gente poderia considerar a Comunicação "a" ciência pós-moderna, ou seja, ela é o lugar onde você reflete, no século XXI, uma dimensão filosófica desse contemporâneo, utilizando para isso inflexôes de variados lugares. Nesse sentido, ela é uma ciência da comunicação, e não o campo da comunicação, que aglutina a possibilidade reflexiva, as teorias e as questóes de variados campos das chamadas Humanidades em torno de um diálogo para tentar explicar as açóes, as ingerências, o mundo contemporâneo, o mundo em que a gente vive. Ela é a filosofia do século XXI nesse sentido também. Nós não nos damos conta da importância teórica desse lugar onde a gente se move. Nós nos colocamos sempre com complexo de inferioridade, como 
se a Comunicação fosse, assim, um primo pobre. A gente precisa da História, a gente precisa da Literatura, a gente precisa da Antropologia. É o contrário! No século XXI, é a Comunicação que reúne uma reflexão sobre esse viver contemporâneo. O mundo hoje é midiatizado, como diz o Muniz [Sodré]. Então, se ele é midiatizado, se as relaçôes humanas se fazem através de relaçôes midiáticas, qual é a disciplina que dá conta de explicar essa midiatização? É a Antropologia? É a Sociologia? É a História? Não, é a Comunicação. Portanto, nós não somos mais o patinho feio das Humanidades. Não é mais História e Comunicação, é Comunicação e História. O que a História faz nada mais é que estudar atos de comunicação, portanto, quem precisa da Comunicação é a História, não é o contrário, porque, o que é que a História estuda? Ela estuda o documento, não é isso? A cultura material, não é isso? O que é tudo isso que do passado chega até o presente? São coisas que, por alguma razão, perduraram porque alguém lá atrás fez um ato de comunicação. Então, o que a História estuda são atos de comunicação. E isso, no século XXI, nesse momento que é encharcado de presentismo, é ainda mais contundente, porque é um mundo que se move a partir de práticas e processos de comunicação. Pensar a dimensão filosófica desse mundo é pensar numa dimensão de comunicação.

Entáo o que poderia ser uma fragilidade da Comunicação, porque ela bebe em várias fontes, hoje, talvez seja a força que ela tem, é isso?

Exatamente.

Em trabalhos de determinados teóricos usados em Comunicaçáo, há uma distinção muito marcada entre auditivo-visual, oral-escrito, letrado-náo-letrado em funçáo do aparecimento da escrita, do alfabeto ou da prensa. Até mesmo certa diferenciaçáo cognitiva é bastante destacada algumas vezes. Tal ideia já recebeu e recebe um conjunto de críticas dentro do nosso campo e em outros, como o da Linguística. Do seu ponto de vista, é preciso relativizar tais oposiçóes em nossas pesquisas? Por quê? Como?

A questão do livro [História da Comunicação no Brasil] é exatamente essa relativização. Nele, a minha tese é mostrar que as práticas de comunicação no Brasil são governadas pelas práticas da oralidade, ou seja, que nós somos orais por excelência e que passamos da oralidade "primária” para a oralidade dos meios de comunicação eletrônicos, até chegar aos eletroeletrônicos e depois aos digitais, sem nunca ter passado pelo letramento. Ora, se digo isso, estou estabelecendo como princípio que não há oposição entre oralidade e letramento. O fato de você ser oral não te obriga no momento seguinte a ser letrado, e as práticas culturais podem se dar em outros tipos de construçôes culturais que não necessariamente envolvam essa visão binária. A impressão que a gente tem é que houve uma oralidade e em seguida, em uma sequência linear e orientada na ideia de uma História tradicional, teria vindo o letramento, depois a revolução da impressão - questão estudada por Elizabeth Eisenstein -, depois os meios eletrônicos e finalmente os digitais. Como se não houvesse possibilidade de não haver necessariamente essa sequência linear. Assim como não há oposição entre cultura letrada e cultura não letrada, tão estudada desde Bakhtin, 
e também por todos os autores que estudam na História a questão da cultura. Esse binarismo é uma interpretação equivocada até das leituras dos próprios autores mais importantes. O que acontece nas teorias da Comunicação, e no campo da Comunicação de uma maneira geral, é um absoluto exagero presentista. As teorias e os estudos da Comunicação são governados por uma visão privilegiada de estudos no tempo presente e consideram o presentismo na perspectiva de [François] Hartog, isto é, um dado regime de historicidade em que você atribui ao contemporâneo uma transformação radical, sem nenhuma relação com tudo o que passou antes. No debate contemporâneo relativo à epistemologia do campo da Comunicação há uma enorme discussão sobre se seria necessária uma teoria própria da Comunicação. Não se trata de universo teórico, se trata de correlação de forças, de debate de capital simbólico, como diz Bourdieu, de afirmaçáo de determinados lugares de fala. Nada tem a ver com a questão stricto sensu teórica. É claro que qualquer disciplina para se conformar precisa de conceitos em que ela se reconheça, mas os conceitos náo são das áreas, os conceitos estão acima dos campos disciplinares, ainda mais no mundo contemporâneo, estabelecido a partir de outros critérios, que se cinde a partir da segunda metade do século XX. Portanto, se o meu contexto é o contexto da Comunicação, o que me interessa é contextualizar as práticas humanas nesse universo da Comunicação. Então, em cima desse contexto, eu vou trabalhando com os outros processos.

Foi bom a senhora ter tocado nesse assunto do presentismo, porque esta é uma pauta recorrente nas discussóes do campo da Comunicaçáo. É impressionante a quantidade de vezes que a palavra "revoluçáo" aparece em estudos da tecnologia digital. Todos eles falam de "a revolução", “a virada", como se tudo fosse inédito, como se todos os processos se dessem por meio de rupturas bruscas...

Bruscas e emblemáticas. Como se nunca tivesse havido nada similar. Quer ruptura maior do que o telégrafo? Quer transformação maior do que a luz elétrica? A luz elétrica permitiu uma série de transformações na relação do leitor com o impresso que a gente não se dá conta. Pessoas lendo ao ar livre à noite era algo impossível no século XIX. A possibilidade de uma leitura mais íntima também vem em decorrência da luz elétrica. São tecnologias que vão transformando as práticas de comunicação. A gente não consegue ver porque não temos um olhar processual. Todas as nossas pesquisas começam do zero! É como se ninguém tivesse pesquisado aquilo antes. Nós simplesmente não olhamos para a formação do nosso campo, para os estudos que se desenvolvem há cinquenta anos. Não é pouco! Quando alguém diz, “Ah, é um campo jovem", eu tenho vontade de rir, porque já tem quase cem anos esse tal campo da Comunicação e eles continuam dizendo isso. É sempre jovem, exatamente, porque não se quer olhar o que foi feito, e quando se olha é para demolir, de maneira a não sobrar nada, pedra sobre pedra. Dessa forma ninguém cresce teoricamente como campo de conhecimento.

No início do livro a senhora diz que nós somos uma sociedade oralizada - "do burburinho das ladeiras e ruelas do século XVIII ao som que 
acompanha os transeuntes das cidades modernas, que insistem em falar em voz alta e nos telefones celulares, existe uma linha de continuidade da sociedade oralizada". Em maio de 2014, O Globo publicou uma matéria com o título "Os corcundas de smartphone", que tratava, de forma bastante representativa, sobre a prática comunicacional contemporânea de troca de mensagens e informaçóes, 24 horas por dia, através de dispositivos eletrônicos, em especial os smartphones. Pensando nisso, a impressáo que fica é a de que a Comunicaçáo tem se voltado para uma face cada vez mais individualista e silenciosa. Apesar disso, a senhora acredita que continuamos a ser uma sociedade oralizada? Quais seriam as distinçóes entre a oralidade do século XVIII e a oralidade do século XXI?

É claro que a gente nunca escreveu nem leu tanto quanto nos tempos atuais. Eu acho que a leitura, hoje, no Brasil, assumiu um patamar que nunca houve na história do país. Pode não ser da forma como tradicionalmente a gente enxerga a leitura ou gostaria que as pessoas lessem - estou me referindo à cultura erudita -, mas isso não quer dizer que essas práticas não sejam de escrita e de leitura. O que as pessoas fazem no What's App, por exemplo, são práticas de escrita, elas estão criando uma nova configuração escrita que vai redundar em transformaçóes corporais, transformaçôes na forma como a gente estabelece a comunicação escrita, o código escrito. Tudo isso vai se transformar com o tempo e as açôes humanas nessa duração vão influenciando nossas práticas de comunicação. Por mais paradoxal que possa parecer, vivemos em uma sociedade cada vez mais global, que elimina a questão do espaço com a possibilidade de estar conectada com todas as partes do mundo, mas que, ao mesmo tempo, está cada vez mais voltada para uma excessiva intimidade, uma intimidação, vamos dizer assim. Tudo isso vai transformando os modos de ser e é aí que você desenvolve as práticas de comunicação. Mas é preciso deixar claro que apesar de vivermos um momento de transformaçôes, essas transformaçóes não foram emblemáticas nem serão as últimas ou as primeiras. Há uma linha de continuidade e de exacerbação, de complexificação dessas transformações ao longo dos últimos, pelo menos, três séculos. O homem não é só produto de sua história, ele também é produto de suas práticas, porque as suas práticas são desenvolvidas nesse universo cultural. Dessa forma, vão se desenvolvendo práticas que refletem esse modo de ser cada vez mais íntimo desse sujeito cultural que está sendo conformado no século XXI.

\section{A senhora poderia dar um exemplo mais claro?}

Vou te dar um exemplo meu, de professora de aluno de graduação. Hoje eu conversei com eles e expliquei que cada geração é de um jeito. Quando você tem 30, 40 anos como professor de graduação, e a cada ano vai se defrontando com meninos de 16, 17 anos, e depois eles têm 30, 40, 50 anos, daqui a pouco você sabe as características de cada grupo. Qual é a característica dessa geração? Eles são de uma geração que não gosta de ficar concentrada em uma mesma atividade. Claro que é diferente em função dos grupos sociais, evidentemente, mas a dispersão talvez seja a característica cognitiva que mais esteja se desenvolvendo neles, exatamente, por mais paradoxal que possa parecer, em 
função desse intimismo já canalizado. Agora, como você anda sempre com outro falando através desses aparatos tecnológicos, você pode ser multitarefa. Até brinco com eles dizendo que eles são a "geração HP", multitarefa, fazem quinhentas coisas ao mesmo tempo, porque os dispositivos tecnológicos ajudam na construção desse tipo de relação comunicacional. Por outro lado, apesar dessa relação intimista com esses novos aparelhos tecnológicos, esse jovem é o mesmo que escuta música nas alturas, que grita nas comunidades populares, sobretudo em determinados lugares culturais. Eu costumo dizer que quem é do Rio de Janeiro náo chama o outro, grita o outro. $\mathrm{O}$ fato de a gente ser tátil, intimista, de estar desenvolvendo outro tipo de relacionamento com as letras, nem diria com o letramento, não nos tira a característica de oralidade, e por isso os aparelhos digitais fazem tanto sucesso. Por que o digital tem tanto apelo? Por que a gente se identifica de uma maneira táo grande com o ato digital? Porque nada é mais oral que o digital. O digital é a exacerbação da perspectiva oral se você for analisar. Um oral que não fala, é um oral numa outra dimensão, ou que não fala no registro que a gente está acostumada enquanto oral. Ele é a exacerbação dessa cultura da oralidade tal como era a televisão em outra dimensão, uma oralidade secundária, por isso fez tanto sucesso.

A pesquisa que a senhora realizou dá ênfase ao sujeito como ator central das práticas de comunicaçáo ao mesmo tempo em que aborda a materialidade dos meios como fator relevante para compreensáo dos processos comunicacionais. Como é possível desenvolver pesquisas que tratam da materialidade sem se aproximar do determinismo tecnológico?

Essa é também uma grande discussão da História, em geral, e não apenas da História da Comunicação. O que é a História? A História é ou a historiografia ou a historicidade. Se a gente pensar que a História é a historicidade, ou seja, a forma como o ser humano se sente na duração, a gente vai dizer que não existe, eu costumo dizer, História das Coisas. Náo existe História da Mesa, não existe História do Jornal, não existe História da Internet. Existe História dos sujeitos humanos que estabelecem relaçáo com as coisas. Então não existe História possível sem a construção ou sem a perspectiva de considerar a materialidade de quem faz e produz a História, que é o ser humano ao viver cotidianamente. Por isso eu não acho que possa existir uma História do Rádio, da Televisão, da Internet, do Jornal. Não existe essa História porque as coisas não tem história, quem tem História é o Homem fazendo as coisas, ou seja, é possível você tentar recuperar uma História a partir de uma cultura material ou por meio de coisas, mas essas coisas, quem fez e deu significado a elas foram os homens. Por isso a História é historicidade. A História não é só uma mera disciplina, a História é uma atitude filosófica diante da vida. Então, se eu considero que a História não é mera disciplina que recupera a verdade absoluta do passado, mas é uma tentativa de compreensão da ação humana no tempo, eu tenho que pensar não na História do Celular, da Materialidade, mas sim na História disto mais isto, que existe porque existem pessoas que neles falam, que neles digitam. O celular em si não tem História, quem tem história são as pessoas que falam no celular e fazem história. 
Nas primeiras décadas após a implementaçáo da prensa tipográfica no Brasil houve um acentuado crescimento no número de periódicos circulando no país. Muito, de acordo com seu livro, devido a posicionamentos políticos e também a uma certa imortalidade que esse registro impresso oferecia ao redator do jornal. De que forma a efemeridade dos registros jornalísticos hoje, nessa era digital, pode afetar a qualidade da notícia e a confiança na informaçáo? A senhora acha que isso interfere?

Eu não acho que seja efêmero. Na verdade, acho que é o contrário. Tudo que cai na rede nunca mais se apaga.

Mesmo que se apague aquela notícia? De vez em quando os textos também são editados e algumas informaçóes desaparecem...

Some a notícia, mas se foi para a rede, nunca mais se apaga, há sempre uma possibilidade daquele link, mesmo apagado, ser retomado. O problema todo não é a efemeridade, é o excesso. Estamos criando uma memória ultrapotente de tudo o que produzimos no mundo, mas náo sei onde poderemos guardar tudo isso. É a questáo do Funes, o Memorioso, de [Jorge Luis] Borges. Então não é efêmero, é o contrário, é a duração eterna dos registros que um dia foram para a rede e jamais poderão ser apagados. Essa é a grande questão. Mesmo que você processe alguém e peça para que retirem aquilo do ar, vai haver um link, uma possibilidade de você acessar aquilo novamente. Essa é a grande questão do mundo contemporâneo, e não o contrário.

O que a senhora está dizendo entáo é que o digital é mais permanente que o impresso, é isso?

Exatamente. O digital ainda é mais duradouro do que o impresso, porque o impresso poderia estar sujeito à má conservação, às traças... Por exemplo, eu estudo os jornais manuscritos. É um verdadeiro milagre eu ter encontrado exemplares desse tipo, porque eles eram, às vezes, um exemplar único e que era manuseado por milhares de pessoas, então, como eles vieram do século XIX para o século XX? Porque algum doido resolveu guardar isso, escondeu num baú e ficou lá, eternamente guardado, nunca mais ninguém mexeu, até que um dia alguém deu aquele baú para a Biblioteca Nacional e lá ficou. Mas a possibilidade de guardar aquilo em um suporte de papel é muito inferior do que em suporte digital. Portanto o digital nada tem de efêmero, o digital, na verdade, é a possibilidade da Biblioteca de Alexandria.

Curioso a senhora dizer isso, porque os historiadores estudaram por muito tempo leituras de homens do passado através de arquivos contendo livros, diários, correspondências, enfim, textos variados que foram preservados em papel - um exemplo disso é o de Robert Darnton e os arquivos da Sociedade Tipográfica de Neuchâtel -, e hoje vemos historiadores questionarem se poderíamos fazer o mesmo com o correio eletrônico, por exemplo. A senhora acredita que os textos digitais podem alterar as condiçóes de resgate das leituras e mesmo dos textos por meio de pesquisas em arquivo? Se sim, como? É possível ver o digital como proporcionador de novas maneiras de acessar os textos? 
Primeiro de tudo, essa pergunta infere uma possibilidade de retomada de fonte do presente pela História em um possível futuro, e isso é uma verdadeira heresia na História, porque na História a gente não trabalha com o "se", ou seja, "se" a gente tem esse comportamento hoje, como será no futuro? Não existe essa possibilidade histórica. A História trabalha com a questáo do tempo, que é tão fundamental para essa área do conhecimento, e com as relaçóes do presente, passado e futuro, que também são outras relaçóes fundamentais à História. Não existe possibilidade de dúvida. As relaçóes do passado, do presente e do futuro se dão para que a gente saiba que houve um passado; houve um passado porque eu, no presente, por exemplo, olho para trás e lembro, pela minha memória - que se constitui em um conector fundamental nessas relaçôes com o passado - que "houve um futuro", porque eu sei que eu não existia aqui um dia e minha máe já existiu no meu passado, que era o futuro dela, então a sequência de gerações me indica também essa relação com o tempo. Mas a História não trabalha com o "se", então eu não posso dizer como será a relação do pesquisador da História no futuro com esses documentos que a gente julga que são efêmeros - e não são efêmeros, como eu disse. Então a pergunta não deve ser feita na perspectiva da História, mas sim na perspectiva da Comunicação, ou seja, qual é a relação que se estabelece hoje entre alguém, um público e as materialidades, a partir desses processos de comunicação? Isso pode ser estudado hoje, não precisa ser estudado para trás e nem numa perspectiva de futuro, basta fazer uma pesquisa empírica para discutir todas essas questões da imaterialidade desse documento, ou da materialidade, essa questão da perenidade da rede.

Em História da Comunicação no Brasil a senhora trata da influência de um pensamento eurocêntrico na análise dos processos comunicacionais brasileiros. Se nós já temos uma vasta gama de pesquisas desenvolvidas em âmbito nacional, como podemos compreender a insistência de muitos trabalhos em privilegiar o olhar europeu? Por que ainda existe esse privilégio? E o que seria essencial para a produçáo de um olhar brasileiro?

A ideia desse livro surgiu durante uma banca que participei na Unesp, em Bauru. A banca era para ingresso de um doutor em História da Comunicação, e quando fui ver a bibliografia do programa me dei conta de que não existia nenhum livro sobre História da Comunicação no Brasil e o único livro que tinha aparecido mais recentemente era o do Peter Burke e Asa Briggs. Eles fizeram um estudo da social da História da Mídia numa perspectiva absolutamente europeia. Mas os processos históricos que ocorreram na Europa Ocidental, como falo logo na Introdução, não foram os mesmos que ocorreram no Brasil. Um exemplo: na Europa Ocidental, a partir do final do século XIX, se desenvolve um modelo ideológico, uma História das Ideias, que Mikhail Bakunin chama de "pensamento autoritário europeu", o qual vai desaguar, por exemplo, no nazifascismo, que nada tem a ver, embora sirva de inspiração para tal, com o conservadorismo brasileiro. E por que não tem a ver com o conservadorismo brasileiro? Porque no caso da Europa, a questão do liberalismo vai tomando uma configuração que mesmo o autoritarismo não coloca por terra a questão 
das individualidades, e muito menos de perceber essas individualidades como atreladas às diferenças entre os seres humanos. Os seres humanos são, por natureza, diferentes. Já no caso brasileiro, o conservadorismo nacional ou a modernização conservadora, como falam alguns, vai beber em duas fontes: tanto no autoritarismo europeu quanto no fato de a gente ter tido três séculos de escravidão. Ora, esses três séculos de escravidão evidentemente vão mudar a forma e o sistema de ideias desse território e vão formar uma sociedade completamente diferente da sociedade europeia. No Brasil houve a naturalização das diferenças, a naturalização de que existem pessoas piores e pessoas melhores; que os melhores devem ensinar aos piores; que os piores são piores porque não têm dinheiro, porque são mais pobres, porque são ignorantes, nordestinos e porque não sabem votar; isso é pensamento conservador brasileiro, que nada tem a ver com o nazismo e com o fascismo.

\section{É tipicamente brasileiro...}

É tipicamente brasileiro. Então, voltando à pergunta, como você vai transportar para o outro a questão da educação? Por exemplo, na Europa o letramento se dá de forma maciça, porque o sistema educacional é desenvolvimento exponencial nos séculos XVIII e XIX. No Brasil, no século XVIII as mulheres não tinham nem escola, as mulheres não podiam sair de casa, os escravos não podiam nem dizer que um dia souberam ler. Agnes Heller diz que conhecimento histórico é uma questão de valor, que é coisa maldita, que ninguém precisa saber. No Brasil ninguém precisa saber que escravo podia ler, que escravo fazia poesia, que escravo assinava. É conhecimento maldito, coisa que ninguém precisa saber. Então, como é que eu vou pegar os processos da Europa Ocidental e transportar para esse lugar que tem uma historicidade toda peculiar, uma construção histórica submetida a ditames extremamente particulares? Por isso que não é possível generalização dos padrôes de explicação contextuais europeus transportados para o território brasileiro. Essa é a principal crítica que eu faço, porque, normalmente, os estudos são feitos por mãos de meia dúzia. Essa que é a questão. São pessoas que não são historiadoras e, portanto, não enxergam que na História existem três conceitos primordiais. Um se chama tempo, o conceito mais fundamental de todos. $\mathrm{O}$ segundo se chama espaço. Espaço social, espaço de relaçóes sociais. Espaço não é meramente geográfico, é espaço de relaçôes culturais, simbólicas, de conformação de um lugar... não é nem um espaço, é um lugar. O terceiro são os grupos sociais. Sem esses três conceitos não se faz História. O que acontece é que os estudos históricos de Comunicação não consideram a dimensão teórica da História e aí, incorre nesses... não posso dizer nem que é erro... nesses equívocos, nesses enganos de abordagem, nesse tipo de generalização.

\section{Quais serão os seus próximos passos, Marialva?}

Tenho três projetos em andamento. Dois estão prontos, mas ainda preciso me desvencilhar das burocracias. Quero escrever sobre as práticas de comunicação dos escravos brasileiros no século XIX, então comecei exatamente pela mais importante de todas, que era a comunicaçáo com os mortos, e que causava uma terrível incompreensão aos europeus. Eles não compreendiam, 
por exemplo, por que na senzala, que era toda fechada, os escravos tinham permanentemente um fogo aceso no chão. Isso, para os europeus, era motivo de completa ignorância. Aquele fogo aceso deixava tudo sujo, deixava tudo preto e, levando-se em consideração que já era um calor danado... Eles não compreendiam que o fogo era a possibilidade de comunicação com os mortos. O fogo era a maior prática de comunicação dos escravos, a possibilidade de comunicação com os ancestrais. Então, eu quero fazer esse projeto que começa exatamente com isso, com esse estranhamento, esse desconhecimento dos europeus com relação a esse universo histórico-cultural, e vai até o final do século XIX, pouco antes da abolição da escravatura. O segundo é um projeto que eu tenho sobre os manuscritos do Brasil. Eu constituí uma rede de pesquisadores que estudam, em vários estados do Brasil, a existência ou náo de periódicos manuscritos e já descobri algumas coisas fantásticas: a existência de periódicos manuscritos no século XVIII, no Maranhão; na Revolta dos Beckman; na Revolução Farroupilha, no Rio Grande do Sul... Só com o que tem na Biblioteca Nacional já dá um bom estudo, mas estou pesquisando também em outros estados para ver que isso não se dava apenas no Rio de Janeiro. É muito difícil localizar os exemplares, mas as referências a eles existem, e os pesquisadores estão tentando ver se os localizam. Se localizarem, a gente vai fazer um belo livro - tipo aquele que o Darnton fez sobre a Revolução Impressa - com os manuscritos no Brasil, com fac simile, e contando um pouco dessa história em que falo que existe uma ordem manuscrita. A gente sempre pensou que ia da oralidade para a impressão. E os manuscritos? Tivemos manuscritos e é muito importante estudá-los. Bem, e o meu mais recente projeto, que ainda está em gestação, é, se a Comunicação trabalha nessa dimensão presentista, eu fiquei pensando, não será o caso de a gente pensar uma História da Comunicação do contemporâneo, ou seja, pensar o contemporâneo, as questóes do contemporâneo, todas essas questôes que são mais emergentes na área da Comunicação, numa perspectiva histórica desses tempos contemporâneos? Acho que o meu terceiro projeto será esse de estudar a história da Comunicação do contemporâneo, assumindo o presentismo da Comunicação e tendo um olhar histórico sobre esse presentismo. Acho que esse vai ser o meu projeto mais importante. 